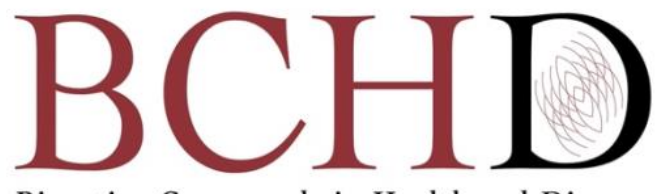

Bioactive Compounds in Health and Disease

\title{
Body weight, vitamin D and zinc: A review of associations with coronavirus disease (COVID-19)
}

\author{
Mona Boaz, Hagit Salem, Daniela Abigail Navarro, and Vered Kaufman-Shriqui
}

Department of Nutrition Sciences, School of Health Sciences, Ariel University, Israel

Corresponding Author: Mona Boaz, PhD, Professor, Department of Nutrition Sciences, School of Health Sciences, Ariel University, Kiryat Hamada 3 Ariel, Israel

Submission Date: August 25 ${ }^{\text {th }}, 2021$; Acceptance Date: September 22 ${ }^{\text {nd }}, 2021$; Publication Date: September $24^{\text {th }}$, 2021

Please cite this as: Boaz M., Salem H., Navarro D.A., Kaufman-Shriqui V. Body weight, vitamin D and zinc: A review of associations with coronavirus disease (COVID-19). Bioactive Compounds in Health and Disease 2021. 4(9): 189-200. DOI: https://www.doi.org/10.31989/bchd.v4i9.839

\begin{abstract}
Obesity has been associated with adverse Coronavirus disease [COVID-19] outcomes; obesity is associated with sub-optimal immune function, including vitamin $D$ and zinc deficiencies, two micronutrients essential for immune function, including anti-viral activity. The co-occurrence of vitamin $\mathrm{D}$ and zinc deficiencies have been documented. These exposures have been widely discussed in both scientific and popular literature. Thus, a critical review of the association between obesity, vitamin D and zinc, in relation to the COVID pandemic, is appropriate. Evidence strongly associates obesity and adverse COVID outcomes including hospitalization, intensive care hospitalization, need for mechanical ventilation and death. While the mechanisms associating vitamin $D$ and zinc to immune function are well-delineated, clinical trials of these nutrients fail to identify efficacy in the prevention or treatment of COVID. Further studies are warranted in susceptible populations. It is important that healthcare professionals practice evidence-based care; thus at this point, neither vitamin D nor zinc can be recommended as a preventive or cure for COVID.
\end{abstract}

Keywords: COVID, body weight, obesity, vitamin D, zinc 


\section{Body weight, Vitamin $D$ and Zinc: a review of associations with Coronavirus Disease (COVID-19)}

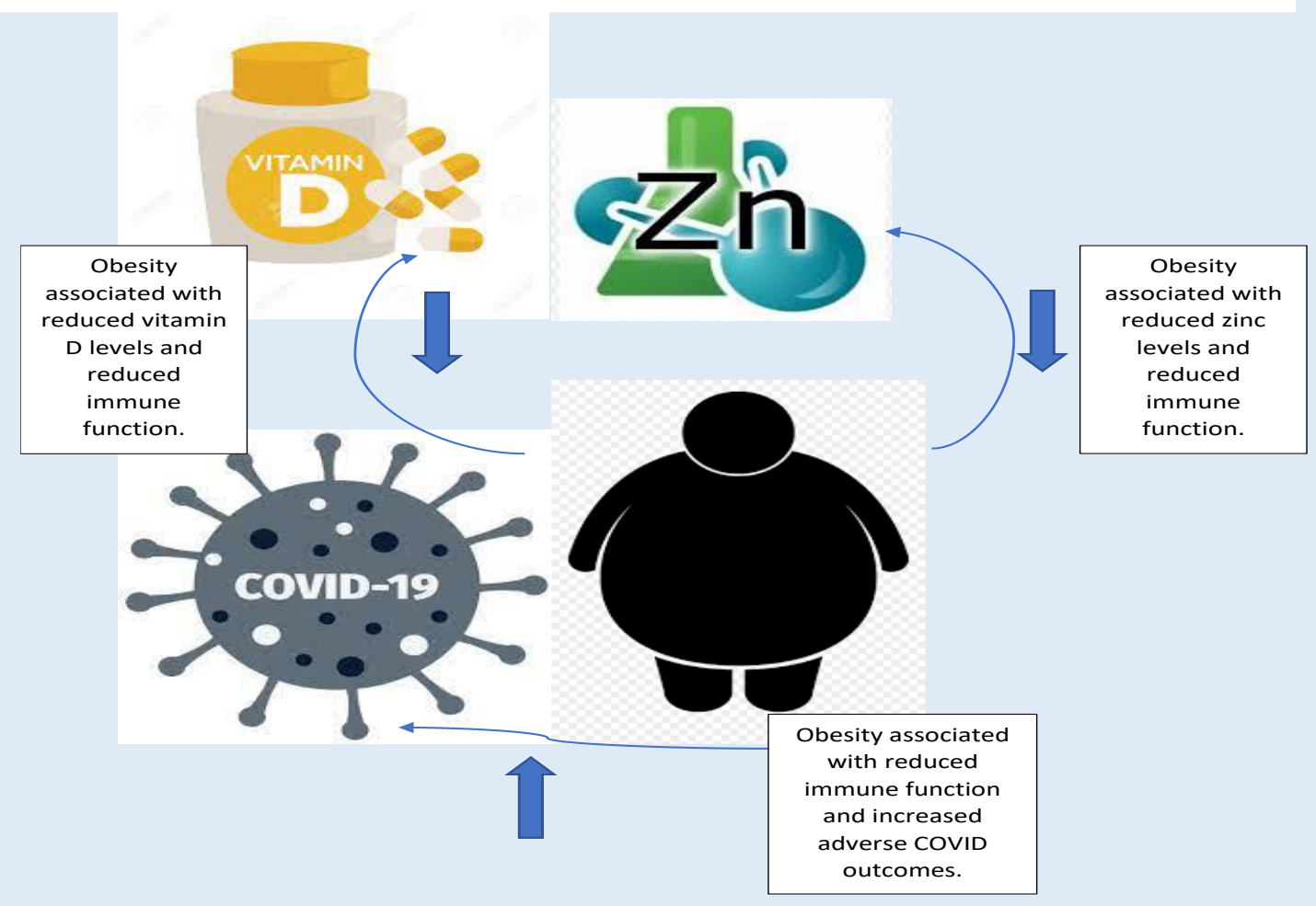

CFFC 2021. This is an Open Access article distributed under the terms of the Creative Commons Attribution 4.0 License (http://creativecommons.org/licenses/by/4.0)

\section{INTRODUCTION}

The global pandemic of SARS-CoV-2 COVID-19 (COVID) has prompted many governments to implement and enforce screening, mitigation, widescale self-isolation and/or suppression strategies in attempts to control the outbreak [1]. This was particularly true prior to the availability of vaccinations; however, the circulation of new variants despite high levels of vaccine uptake has led to the re-implementation of varying intensities of lockdown strategies, with poor suppression of transmission [2]. Both the outbreak itself, which exposed the public to a here-to-for unknown pathogen, and the governmental response to the outbreak, which caused economic and social devastation, were [and remain] sources of anxiety [3].

As a result of the lockdowns, many people reported alterations in their usual dietary and physical activity routines, many reporting weight gain during this period [4]. The long-term impact of these changes has not yet been evaluated. In addition to alterations in body weight, the pandemic is typified by a great deal of online information about the role of specific nutrients in COVID prevention and treatment, particularly Vitamin D and Zinc. Conceptually, an association between obesity and adverse COVID outcomes have been identified [5]; obesity is associated with sub-optimal immune function, including deficiencies in vitamin D and zinc [6-7]. Both vitamin $D$ and zinc are essential for immune function and have documented anti-viral properties [8]; important metabolic associations between vitamin D and zinc have been identified [9], and the co-occurrence of vitamin $D$ and zinc deficiencies have been documented [10].

Thus, the objective of the present review is to assess the impact of energy intake, body weight, 
vitamin D, and zinc nutriture on COVID prevention and treatment in the general population.

\section{Energy Intake and Body Weight Change During}

COVID: An association between overweight/obesity and adverse COVID outcomes including hospitalization, ventilation, and death, was identified early in the pandemic [11]. Specifically, computed tomography (CT)-measured visceral fat and intramuscular fat have been shown to be positively associated with adverse outcomes from COVID [12]. By contrast, one study found that epicardial adipose tissue attenuation is a marker of inflammation, but not obesity, predicted admission to intensive care among COVID patients who underwent CT for pneumonia [13].

An international survey of dietary changes during the pandemic was conducted during the first quarter of 2020 and included almost 4000 participants. Available in seven languages, the survey examined self-reported changes in diet quality. It was measured using a modified Mediterranean Diet Score and associated these changes with anxiety as measured using the General Anxiety Disorder (GAD) scale [14]. Almost $25 \%$ of respondents reported weight gain, while $17.2 \%$ reported weight loss. The anxiety score was significantly inversely associated with the total diet quality score, indicating that individuals who reported diets closer to the Mediterranean Diet pattern experienced (or at least reported)] less anxiety. When individual diet score components were examined, consumption of the following items was significantly positively associated with anxiety: butter, margarine or cream, sweetened beverages; red meat; alcoholic beverages; savory baked goods; and salty snacks. On the other hand, consumption of the following items was significantly inversely associated with anxiety: fish, nuts, hummus, tahini, or refried beans. People who reported that their diet during the pandemic was of poorer quality than their diet prior to the pandemic also reported greater anxiety. Similarly, those who reported weight gain (but not weight loss) during the pandemic reported greater anxiety. These findings persisted even after controlling for potential confounders such as age, sex, and the language in which the survey was completed.

A meta-analysis including more than 45,000 individuals in 30 studies assessed the impact of body mass index [BMI] -defined obesity (BMI $\geq 30$ $\mathrm{kg} / \mathrm{m}^{2}$ ) or visceral adipose tissue (VAT)-defined adiposity on adverse COVID outcomes, including hospitalization, intensive care unit (ICU) admission, mechanical ventilation, or death [15]. In univariate analyses, BMI-defined obesity significantly increased odds of adverse outcome by $67 \%$. These findings remained robust in multivariate analyses. To assess the impact of VAT on COVID outcomes, the standardized mean difference (SMD) was used, which is an estimate of effect size. To calculate the SMD, the placebo improvement is subtracted from the new treatment improvement, and the difference is divided by the pooled standard deviation of the two measures [16]. Thus, if the SMD is greater than zero, one can conclude that the new treatment is more effective than placebo; on the other hand, if the SMD is less than zero, one can conclude that the new treatment is less effective than the placebo. Patients with VAT-defined obesity can be conceived of as the new treatment group, while patients without VAT-defined obesity can be conceived of as the placebo group. People with severe COVID had significantly greater VAT accumulation, and overall SMD for severe COVID (requiring hospitalization, ICU admission, mechanical ventilation, or death) was 0.50 (95\% Cl: $0.33,0.68 ; \mathrm{P}<0.001)$, indicating significantly greater risk for poor outcomes in people with VAT-defined obesity.

Overall, obesity has been consistently associated with increased risk for poor COVID outcomes, particularly in individuals with comorbidities. This may underpin some of the increased anxiety identified in individuals with weight gain during the pandemic. It has been 
suggested that the mechanism explaining this association is driven by insulin resistance and increased circulating inflammatory cytokines [17]. It has not been shown that weight loss reduces anxiety; on the contrary, reduced food intake prior to hospitalization has been identified as a predictor of poor outcomes in patients admitted with COVID; moreover, obesity was found to be protective against in-hospital mortality among people without comorbidities [18].

Vitamin D: Technically a hormone rather than a vitamin, Vitamin $D$ can be generated in the skin when the precursor molecule absorbs light energy [19]. Vitamin D can also be absorbed from food, such as fatty fish and fortified foods [20]. Well known for its role in bone metabolism, vitamin $D$ is also essential for innate immune function [21].

Innate immunity, the body's initial and immediate response to a pathogenic challenge, involves the complement system and includes neutrophil and macrophage antimicrobial responses. Monocytes and macrophages can phagocytose pathogens [22]. Additionally, they can sense pathogen-associated molecular patterns from bacteria, parasites, fungi, and viruses [23]. Vitamin D enhances innate immunity by inducing anti-viral peptides, including NOD2/CARD15-defensin $\beta 2$ [24] and cathelicidin [25], thereby improving mucosal defenses.

In addition to the role of vitamin D in innate immunity, deficient serum vitamin $D$ is associated with both increased autoimmunity [26] and increased susceptibility to infection [27]. Vitamin D has also been shown to inhibit cytokine storms [28].

The winter outbreak pattern typical of influenza $A$ is explained by the seasonal stimulus hypothesis. According to this theory, influenza A outbreaks correspond to seasonal reduction in sun exposure, reducing vitamin D levels, and suppressing immune response [29]. While the seasonality of COVID-19 has not yet been established, associations with sun exposure have been reported. An ecologic study used proximity to the equator as an estimation of mean sun exposure and correlated this to COVID-19 mortality in 88 countries. The association was attributed to alterations in Vitamin D levels associated with sun exposure [30]. This concept is further supported by observations regarding increased COVID-19 mortality among individuals with darker skin [31]. Indeed, it has been shown that vitamin D deficiency was almost nine times more prevalent among lower non-Hispanic African Americans than non-Hispanic Caucasians [32]. Particularly vulnerable are elderly individuals, among whom pre-existing, ageassociated immune dysregulation coupled with vitamin D deficiency explained increased COVID-19 mortality rates [33]. It is noteworthy that sun exposure among the elderly, particularly those who live in long-term care facilities, is less than that of other individuals [34].

Investigators studied four patients with vitamin D deficiency diagnosed with COVID-19 in April 2020 and treated them with either low dose (1000 I/U) or high dose $(50,000 \mathrm{I} / \mathrm{U})$ vitamin D for five days. Patients who received high dose vitamin D achieved normalization of vitamin D levels, shorter hospital stay, lower supplemental oxygen requirement, and reduced blood markers of inflammation [35]. While case series are not actually research (no hypothesis is tested), this encouraging report no doubt encouraged further research in the use of vitamin D as a therapeutic in COVID-19.

Cross-sectional studies measure exposure and outcome simultaneously. This study design was ideal in the early phase of the COVID-19 pandemic when longitudinal data were not available. In one such study, investigators noted that hospitalized individuals with vitamin D deficiency were 4.6 times more likely to be positive for COVID-19 than their non-vitamin D deficient counterparts. This association persisted after controlling for potential confounders, including age, sex, and comorbidities [36]. Similarly, vitamin D deficiency defined as $<30$ $\mathrm{nmol} / \mathrm{L}$, increased the risk of severed COVID-19 by 
a factor of 2.72. This association remained robust even after controlling for age and sex [37].

These findings support the notion of an association between vitamin $\mathrm{D}$ deficiency and risk for COVID-19 and disease severity but cannot establish causality. By definition, when exposure and outcome are contemporaneously measured, temporality cannot be established, a prerequisite to determining causality.

Several retrospective studies have been reported on the association between vitamin $D$ and COVID-19. One study compared vitamin D levels in COVID-19 patients by vital status (recovered vs. deceased). An overall difference in vitamin D levels was not identified; however, among individuals with severe COVID-19, vitamin D levels were lower among those who died than among those who ultimately recovered [38]. In a large retrospective study in the US, vitamin D levels ascertained prior to COVID-19 testing did not differ between white individuals who tested positive or negative for COVID 19; however, among Black participants, those with vitamin $D$ levels $<40 \mathrm{ng} / \mathrm{mL}$ were at increased risk of a positive COVID-19 test [39]. Another retrospective study conducted in individuals enrolled in a New York City Health System and positive for COVID-19 found that vitamin D deficiency, defined as levels $<20 \mathrm{ng} / \mathrm{mL}$, increased the risk of needing oxygen support therapy, but not for hospitalization or death [40].

Compared to cross-sectional studies, retrospective studies suggest that the association between vitamin D levels and COVID-19 outcomes is nuanced. It becomes clear that the association might be conditional on patient characteristics such as race. However, retrospective studies are limited to individuals with a measure of vitamin D status prior to the ascertainment of COVID-19 status. Such individuals may be at different risk for COVID-19 than others due to comorbidities or medical followup. This would impact the external validity of the findings.
Prospective studies begin with the exposure, in this case, vitamin D levels, and follow participants forward in time to ascertain the outcome. Due to them begining with the exposure, temporality can be firmly established, permitting determination of causality.

One prospective study of 410 patients admitted for COVID-19 categorized vitamin D levels as deficient $(<20 \mathrm{ng} / \mathrm{mL}$ ) or not based on blood tests obtained at hospital admission. These admission serum vitamin $\mathrm{D}$ levels did not correlate with inflammatory markers or clinical outcomes, including death [41]. By contrast, another prospective study found that habitual vitamin D supplementation was significantly associated with reduced risk of subsequent COVID-19 infection; however, blood vitamin D levels and genetically predicted blood vitamin $D$ levels were not associated with COVID-19 risk. It cannot be ruled out that self-supplementation with vitamin D represents some other behavior associated with reduced COVID-19 risk, because vitamin D levels and predicted vitamin $D$ levels did not differ by vitamin D supplementation [42]. Randomized clinical trials provide convincing evidence for the efficacy for interventions by reducing confounding and isolating the influence of the therapeutic or preventive exposure.

In a clinical trial, 240 individuals were randomized to treatment with a single dose of 200 000 IU of vitamin D3 or placebo. The trial was designed to examine the efficacy of this intervention on duration of hospital stay, defined as the number of days from admission to discharge. This outcome did not differ by treatment assignment. While vitamin D levels increased dramatically in the active treatment group vs. placebo, differences in secondary endpoints, including mortality, need for mechanical ventilation or admission to intensive care unit, did not differ by vitamin D treatment [43].

In a pilot study, 50 patients were randomized to treatment with oral calcifediol [0.532 mg] 
beginning on the day of admission, then on days 3 and 7, and weekly thereafter. The control group received neither placebo nor comparator treatment. Of the 50 patients treated with calcifediol, one required admission to the ICU (2\%), compared to 13 of the 26 patients who received no treatment. This represents a relative reduction of ICU admission risk of $98 \%$, an association that remained robust after controlling for comorbid type 2 diabetes or hypertension. No deaths were observed in the calcifediol group, while two deaths were observed in the control group among the 13 patients who had been admitted to ICU [44].

Overall, it can be concluded that while vitamin D is clearly associated with immune function, its efficacy in the prevention or treatment of COVID has not yet been demonstrated in clinical trials.

Zinc: Both animal and clinical studies have demonstrated the role of Zinc in a variety of biological processes as a a signaling molecule, a cofactor, and as a structural element. Zinc, an essential element, is distributed largely in muscle and bone, and secondarily in the skin and liver; almost all located intracellularly [45]. Adequate zinc nutriture is essential for normal growth and development in infants and children, and is involved in cell differentiation, especially in tissues typified by rapid proliferation such as gastrointestinal cells and cells involved in immunity [46]. Metabolically ubiquitous, zinc has been shown to be essential to more than 300 enzymic reactions, including the function of metalloproteins and the induction of oxido-reductase, hydrolase ligase, lyase, superoxide dismutase and phospholipase $C$ [47]. Zinc finger motifs stabilize protein subdomains, facilitating interaction with other proteins [48]. Zinc can form complexes with proteins and nucleic acids; participate in the transmission and regulation of genes; regulate the storage, synthesis and action of peptide hormones; and maintain structural membranes [49].
In addition to its role in immune function, it is perhaps the role of zinc in the maintenance of taste and smell that targeted it as a potential preventive or therapeutic for COVID. Zinc deficiency has been associated with impaired immune function, delayed wound healing, and smell and taste disturbances in the elderly [50]. Zinc deficiency has been associated with risk for pneumonia in elderly individuals [51]. Both olfactory dysfunction and dysgeusia have been identified as early diagnostic signs of COVID, particularly when simultaneously present [52].

These functions associated with zinc deficiency have prompted studies of zinc in the prevention and treatment of COVID. The concept is that "immunity boosters," including zinc, can prevent COVID by stimulating T-cells, B-cells, and neutrophils; neutralizing free radicals, promoting cytokine proliferation and inhibiting immunosuppression [53]. Zinc has been identified as having a possible role in preventing viral attachment, penetration, infection, and replication [54]. Zinc is an important component of nutritionbased immunity and individuals deficient in zinc are at increased risk for viral infection [55].

The antiviral properties of zinc have largely been studied in viruses other than COVID [56]. Thus, the processes through which this mineral may prevent/treat COVID is largely extrapolatory. COVID infection begins in the respiratory epithelium, where the virus binds to angiotensin converting enzyme 2 (ACE2) receptors, activating nuclear factor kappa-light-chain-enhancer of activated B cells (NF-kB), which, in turn, induces expression of pro-inflammatory genes. Zinc inhibits NF-kB, thus diminishing the inflammatory response, preventing the "cytokine storm" [57]. From this mechanism, it has been proposed that zinc supplementation could both prevent disease and mitigate symptoms in individuals who have become infected with COVID [58].

A randomized, controlled clinical trial provides the best format in which to directly test the efficacy 
of an intervention. One clinical trial conducted in a single health care system aimed to test whether treatment with zinc and/or vitamin $\mathrm{C}$ could reduce the severity and/or duration of symptoms in 214 adult outpatients with COVID [59]. All participants were positive for COVID using PCR and were randomized to one of four groups: zinc gluconate (50 mg/day); ascorbic acid (8000 mg/day), both; or neither. Patients were followed prospectively to determine the number of days necessary to achieve a $50 \%$ reduction in symptom severity score on which each of the following indicators was rated on a 4-point scale: fever, cough, shortness of breath and fatigue. Secondarily, the following outcomes were assessed: days required to achieve a total symptom score of 0 ; cumulative symptom severity score on Day 5; hospitalization; death; prescribed medications; and adverse events associated with the study interventions. A $50 \%$ reduction in symptom severity score was achieved at 5.9 \pm 4.9 days in the zinc group; $5.5 \pm 3.7$ days in the ascorbic acid group; $5.5 \pm 3.4$ days in the group receiving both interventions; and $6.7 \pm 4.4$ days in the group that received neither intervention $(p=0.45)$. The study was stopped for lack of benefit.

A meta-analysis reported a lack evidence for the efficacy of zinc supplementation for COVID treatment [60]. In this analysis, which included four published studies (including the above-mentioned study) and 1474 participants, found that among zinc-treated participants, survival to hospital discharge was $56.8 \%$ vs. $75.9 \%$ in the comparator group; in-hospital death was $22.3 \%$ in zincsupplemented individuals vs. $13.6 \%$ in the comparator group; neither of these comparisons was statistically significant. The difference in duration of hospital stay was significant: $7.7 \pm 3.7$ days in zinc-treated participants vs. $7.2 \pm 3.9$ days in the standard treatment group $(p<0.001)$.

\section{DISCUSSION}

Good nutrition and maintenance of a healthy body weight is essential for immune function, both supporting resistance to infectious disease and reducing adverse outcomes in the event of illness. Associated with general well-being, good nutrition may facilitate better coping skills and reduce anxiety during lockdowns [61]. It can safely be stated that achieving and maintaining a healthy body weight and ensuring consumption of a high quality diet including a variety of fruit and vegetables, is always prudent [62].

BMI has been established as a risk factor for adverse COVID outcomes, including increased risk for hospitalization [63], ICU admission [64], mechanical ventilation [65] and death [66]. Additionally, the pandemic appears to be increasing obesity levels [67], a phenomenon that could prompt public health officials to conceive of preventive interventions.

Adequate vitamin D nutriture in the context of a healthy diet should be emphasized, particularly in individuals with demonstrated vitamin $D$ deficiency. It is important to remember, however, that indiscriminate supplementation is not without potential harm; indeed, hypervitaminosis D can occur [68]. Several mechanisms through which vitamin $D$ influences the human immune system have been delineated; however, evidence of its preventive or therapeutic efficacy in human populations with COVID-19 is currently lacking. Nevertheless, individuals with inadequate vitamin D nutriture should consult with a health professional regarding appropriate diet and supplemental sources to ensure adequate intake. Zinc is also essential to optimal immune system function. While approximately $15 \%$ of US adults are zinc deficient [69], the majority are not. Groups at increased risk for zinc deficiency include people with Crohn's disease or ulcerative colitis [70]; individuals who have undergone bariatric surgery [71]; vegetarians [72]; and alcoholics [73]. Clearly there is room to assess zinc nutriture in these vulnerable groups and to study the need for supplementation in the face of the pandemic. 
Table 1: Summary of main clinical findings.

\begin{tabular}{|c|c|c|}
\hline \multicolumn{3}{|c|}{ Body weight/BMI and COVID risk } \\
\hline Authors [reference] & Main Findings & Conclusions \\
\hline $\begin{array}{l}\text { Kaufman-Shriqui et al. } \\
\text { [14] }\end{array}$ & $\begin{array}{l}\text { Participants with poor diet quality and/or } \\
\text { weight gain reported greater anxiety. }\end{array}$ & \multirow{2}{*}{$\begin{array}{l}\text { Obesity increases risk of adverse } \\
\text { COVID outcomes; evidence that } \\
\text { weight loss will reduce COVID risk } \\
\text { after infection is lacking }\end{array}$} \\
\hline Huang et al. [15] & $\begin{array}{l}\mathrm{BMI} \geq 30 \mathrm{~kg} / \mathrm{m}^{2} \text { significantly increased risk } \\
\text { of any adverse outcome was } 67 \% \text { in people } \\
\text { with } \mathrm{BMI} \geq 30 \mathrm{~kg} / \mathrm{m}^{2} \text {. }\end{array}$ & \\
\hline \multicolumn{3}{|l|}{ Vitamin D and COVID risk } \\
\hline Authors [reference] & Main Findings & Conclusions \\
\hline Whittemore PB [30] & $\begin{array}{l}\text { Variability in COVID rates attributable to } \\
\text { sun exposure. }\end{array}$ & \multirow{6}{*}{$\begin{array}{l}\text { It is biologically plausible that } \\
\text { vitamin } D \text {, which has anti-viral } \\
\text { activity and supports immune } \\
\text { function, would function in the } \\
\text { prevention/treatment of COVID; } \\
\text { however, better designed studies do } \\
\text { not support this association. }\end{array}$} \\
\hline $\begin{array}{l}\text { Ayoubkhani D et al. } \\
\text { [31] }\end{array}$ & $\begin{array}{l}\text { Increased COVID risk in individuals with } \\
\text { darker skin. }\end{array}$ & \\
\hline $\begin{array}{l}\text { Ohaegbulam KC et al. } \\
\text { [35] }\end{array}$ & $\begin{array}{l}\text { Case series: patients treated with high dose } \\
\text { (>5000 I/U day) vitamin D achieved } \\
\text { normalization of vitamin D levels, shorter } \\
\text { hospital stay, lower supplemental oxygen } \\
\text { requirement, and reduced blood markers } \\
\text { of inflammation. }\end{array}$ & \\
\hline Tehrani S et al. [38] & $\begin{array}{l}\text { Retrospective study: patients who died } \\
\text { from COVID had lower vitamin D levels than } \\
\text { those who survived. }\end{array}$ & \\
\hline Jevalikar G et al. [41] & $\begin{array}{l}\text { Prospective study: blood vitamin D levels } \\
\text { did not predict COVID outcomes }\end{array}$ & \\
\hline Murai IH [43] & $\begin{array}{l}\text { Clinical trial: subjects randomized to } \\
\text { vitamin D had increased blood vitamin D } \\
\text { levels but did not differ from subjects } \\
\text { randomized to placebo in terms of hospital } \\
\text { stay, intensive care admission, need for } \\
\text { mechanical ventiallation or death }\end{array}$ & \\
\hline \multicolumn{3}{|l|}{ Zinc and COVID risk } \\
\hline Authors [reference] & Main Findings & Conclusions \\
\hline Thomas S et al. [59] & $\begin{array}{l}\text { Clinical trial: subjects randomized to } \\
\text { treatment with high dose zinc, vitamin C, } \\
\text { both, or neither. Time to achieve a } 50 \% \\
\text { reduction in symptom severity score } \\
\text { (primary endpoint) did not differ by } \\
\text { treatment. Secondary endpoints including } \\
\text { death, hospitalization and adverse events } \\
\text { also did not differ by treatment. The study } \\
\text { was terminated due to lack of benefit. }\end{array}$ & \multirow[t]{2}{*}{$\begin{array}{l}\text { Like vitamin D, zinc is a biologically } \\
\text { plausible intervention due to its } \\
\text { immunomodulatory and anti-viral } \\
\text { effects. However, intervention } \\
\text { studies and a meta-analysis fail to } \\
\text { demonstrate efficacy. }\end{array}$} \\
\hline Szarpak L et al. [60] & $\begin{array}{l}\text { This meta-analysis included } 1474 \\
\text { participants from four studies. Zinc-treated } \\
\text { patients did not differ from controls by in- } \\
\text { hospital death or survival to hospital } \\
\text { discharge. Compared to controls, zinc- } \\
\text { treated patients had significantly longer } \\
\text { duration of hospitalization }\end{array}$ & \\
\hline
\end{tabular}




\section{CONCLUSIONS}

The main clinical findings discussed herein are summarized in Table 1. As can be seen, while excess body weight emerges as a clear risk factor for COVID and its outcomes, there is little evidence

Abbreviations: ACE2: angiotensin converting enzyme 2, BMI: body mass index, COVID-19: Coronavirus Disease, CT: computed Tomography, GAD: Generalized Anxiety Disorder, ICU: Intensive Care Unit, NF-kB: nuclear factor kappa-light-chainenhancer of activated B cells, SMD: standardized mean difference, VAT: visceral adipose tissue

Authors' Contributions: MB - conceptualization, research, writing; HS - research, editing; DAN research, editing; VKS - research, editing.

Competing Interests: The authors have no competing interests.

Acknowledgment/Funding: This article was not funded.

\section{REFERENCES}

1. Santeramo FG, Tappi M, Lamonaca E: On the management of COVID-19 pandemic in Italy. Health Policy 2021.125(8):995-1001. doi: 10.1016/j.healthpol.2021.05.014

2. Paton C: 'We did everything we could': An account of toxic leadership. Int J Health Plann Manage 2021. Jul 6. doi: 10.1002/hpm.3264.

3. Qiu J, Shen B, Zhao M, Wang Z, Xie B, Xu Y: A nationwide survey of psychological distress among Chinese people in the COVID-19 epidemic: implications and policy recommendations. Gen Psychiatr 2020. 33(2):e100213. doi: 10.1136/gpsych2020-100213.

4. Bhutani S, Cooper JA, vanDellen MR: Self-reported Changes in Energy Balance Behaviors during COVID19-related Home Confinement: A Cross-sectional Study. Am J Health Behav 2021. 45(4):756-770. doi: 10.5993/AJHB.45.4.14.

5. Dalamaga M, Christodoulatos GS, Karampela I, Vallianou N, Apovian CM: Understanding the CoEpidemic of Obesity and COVID-19: Current Evidence, at this time that specific micronutrients, particularly vitamin D and zinc, alter COVID-associated outcomes. Further studies are warranted in susceptible populations

Comparison with Previous Epidemics, Mechanisms, and Preventive and Therapeutic Perspectives. Curr Obes Rep 2021. 28:1-30. doi: 10.1007/s13679-02100436-y.

6. Aghili SMM, Ebrahimpur M, Arjmand B, Shadman Z, Pejman Sani M, Qorbani M, Larijani B, Payab M: Obesity in COVID-19 era, implications for mechanisms, comorbidities, and prognosis: a review and meta-analysis. Int J Obes (Lond) 2021. 45(5):9981016. doi: 10.1038/s41366-021-00776-8.

7. Burris D: Zinc deficiency contributes to chronic inflammation in obesity. Knowledge Bank 2011. https://kb.osu.edu/handle/1811/49029.

8. Costagliola G, Nuzzi G, Spada E, Comberiati P, Verduci E, Peroni DG: Nutraceuticals in Viral Infections: An Overview of the Immunomodulating Properties. Nutrients 2021. 13(7):2410. doi: $10.3390 /$ nu13072410

9. Martín Giménez VM, Bergam I, Reiter RJ, Manucha W. Metal ion homeostasis with emphasis on zinc and copper: Potential crucial link to explain the nonclassical antioxidative properties of vitamin D and melatonin. Life Sci 2021. 281:119770. doi: 10.1016/j.Ifs.2021.119770.

10. Shams B, Afshari E, Tajadini M, Keikha M, Qorbani M, Heshmat R, Motlagh ME, Kelishadi R: The relationship of serum vitamin $D$ and Zinc in a nationally representative sample of Iranian children and adolescents: The CASPIAN-III study. Med J Islam Repub Iran 2016. 30:430.

11. Steinberg E, Wright E, Kushner B: In Young Adults with COVID-19, Obesity Is Associated with Adverse Outcomes. West J Emerg Med 2020. 21(4):752755. doi: 10.5811/westjem.2020.5.47972.

12. Bunnell KM, Thaweethai T, Buckless C, Shinnick DJ, Torriani M, Foulkes AS, Bredella MA: Body composition predictors of outcome in patients with COVID-19. Int J Obes (Lond) 2021. 9:1-6. doi: 10.1038/s41366-021-00907-1.

13. Conte C, Esposito A, De Lorenzo R, Di Filippo L, Palmisano A, Vignale D, Leone R, Nicoletti V, Ruggeri A, Gallone G, Secchi A, Bosi E, Tresoldi M, Castagna A, Landoni G, Zangrillo A, De Cobelli F, Ciceri F, Camici P, Rovere-Querini P: Epicardial adipose tissue characteristics, obesity and clinical outcomes in 
COVID-19: A post-hoc analysis of a prospective cohort study. Nutr Metab Cardiovasc Dis 2021. 31(7):21562164. doi: 10.1016/j.numecd.2021.04.020.

14. Kaufman-Shriqui V, Navarro DA, Raz O, Boaz M: Dietary changes and anxiety during the coronavirus pandemic: a multinational survey. Eur J Clin Nutr 2021. 19:1-9. doi: 10.1186/s13584-021-00461-1.

15. Huang $Y$, Lu $Y$, Huang $Y M$, Wang $M$, Ling $W$, Sui $Y$, Zhao $\mathrm{H}$ :. Obesity in patients with COVID-19: a systematic review and meta-analysis. Metabolism 2020. 113:154378. doi: 10.1016/j.metabol.2020.154378.

16. Faraone SV: Interpreting estimates of treatment effects: implications for managed care. P T 2008. 33(12):700-11.

17. Uzzan M, Corcos O, Martin JC, Treton X, Bouhnik Y: Why is SARS-CoV-2 infection more severe in obese men? The gut lymphatics - Lung axis hypothesis. Med Hypotheses 2020. 144:110023. doi: 10.1016/j.mehy.2020.110023.

18. Caccialanza R, Formisano E, Klersy C, Ferretti V, Ferrari A, Demontis S, Mascheroni A, Masi S, Crotti S, Lobascio F, Cerutti N, Orlandoni P, Dalla Costa C, Redaelli E, Fabbri A, Malesci A, Corrao S, Bordandini L, Cereda E, NUTRI-COVID19 Collaborative Working Group: Nutritional parameters associated with prognosis in non-critically ill hospitalized COVID-19 patients: The NUTRI-COVID19 study. Clin Nutr 2021. S0261-5614(21)00316-2. doi: 10.1016/j.clnu.2021.06.020.

19. Bikle DD: Vitamin D metabolism, mechanism of action, and clinical applications. Chem Biol 2014. 21:319-29. doi: 10.1016/j.chembiol.2013.12.016.

20. Lehmann U, Gjessing HR, Hirche F, Mueller-Belecke A, Gudbrandsen OA, Ueland PM, Mellgren G, Lauritzen L, Lindqvist $H$, Hansen AL, Erkkilä AT, Pot GK, Stangl GI, Dierkes J: Efficacy of fish intake on vitamin D status: a meta-analysis of randomized controlled trials. Am J Clin Nutr 2015. 102:837-47. doi: 10.3945/ajen.114.105395

21. Smith TJ, McClung JP: Nutrition, Immune Function, and Infectious Disease. Med J (Ft Sam Houst Tex) 2021. (PB 8-21-01/02/03):133-136.

22. Caponegro MD, Thompson KK, Tayyab M, Tsirka SE: A Rigorous Quantitative Approach to Analyzing Phagocytosis Assays. Bio Protoc 2020. 10:e3698. doi: 10.21769/BioProtoc.3698.

23. Kawai T, Akira S: The role of pattern-recognition receptors in innate immunity: update on Toll-like receptors. Nat Immunol 2010. 11:373-84. doi: 10.1038/ni.1863.
24. Wang T.-T., Dabbas B., Laperriere D., Bitton A.J., Soualhine H., Tavera-Mendoza L.E: Direct and indirect induction by 1,25-dihydroxyvitamin D3 of the NOD2/CARD15-defensin $\beta 2$ innate immune pathway defective in Crohn disease.J Biol Chem 2010. 85:2227-2231. doi: 10.1074/jbc.C109.071225.

25. Gombart AF, Borregaard N, Koeffler HP: Human cathelicidin antimicrobial peptide (CAMP) gene is a direct target of the vitamin $\mathrm{D}$ receptor and is strongly up-regulated in myeloid cells by 1,25dihydroxyvitamin D3. FASEB J 2005. 19:1067-1077. doi: 10.1096/fj.04-3284com.

26. Fang F, Chai Y, Wei H, Wang K, Tan L, Zhang W, Fan Y, Li F, Shan Z, Zhu M: Vitamin D deficiency is associated with thyroid autoimmunity: results from an epidemiological survey in Tianjin, China. Endocrine 2021. 73(2):447-454. doi: 10.1007/s12020-02102688-z.

27. Muthuvattur Pallath $M$, Ahirwar AK, Chandra Tripathi S, Asia P, Sakarde A, Gopal N: COVID-19 and nutritional deficiency: a review of existing knowledge. Horm Mol Biol Clin Investig 2021. 42(1):77-85. doi: 10.1515/hmbci-2020-0074.

28. Jain SK, Micinski D, Parsanathan R: I-Cysteine Stimulates the Effect of Vitamin D on Inhibition of Oxidative Stress, IL-8, and MCP-1 Secretion in High Glucose Treated Monocytes. J Am Coll Nutr 2021. 40(4):327-332. doi: 10.1080/07315724.2020.1850371.

29. Cannell JJ, Vieth R, Umhau JC, Holick MF, Grant WB, Madronich S, Garland CF, Giovannucci E: Epidemic influenza and vitamin D. Epidemiol Infect 2006. 134:1129-40. doi: 10.1017/S0950268806007175.

30. Whittemore PB: COVID-19 fatalities, latitude, sunlight, and vitamin D. Am J Infect Control 2020. 48:1042-1044. doi: 10.1016/j.ajic.2020.06.193.

31. Ayoubkhani D, Nafilyan V, White C, Goldblatt P, Gaughan C, Blackwell L, Rogers N, Banerjee A, Khunti K, Glickman M, Humberstone B, Diamond I: Ethnicminority groups in England and Wales-factors associated with the size and timing of elevated COVID-19 mortality: a retrospective cohort study linking census and death records. Int J Epidemiol 2021. 49:1951-1962. doi: 10.1093/ije/dyaa208.

32. Herrick KA, Storandt RJ, Afful J, Pfeiffer CM, Schleicher RL, Gahche JJ, Potischman N: Vitamin D status in the United States, 2011-2014. Am J Clin Nutr 2019. 110:150-157. doi: 10.1093/ajcn/nqz037.

33. Meftahi GH, Jangravi Z, Sahraei H, Bahari Z: The possible pathophysiology mechanism of cytokine storm in elderly adults with COVID-19 infection: the 
contribution of "inflame-aging". Inflamm Res 2020. 69:825-839. doi: 10.1007/s00011-020-01372-8.

34. Samefors $M$, Tengblad A, Östgren $\mathrm{CJ}$ : Sunlight Exposure and Vitamin D Levels in Older People- An Intervention Study in Swedish Nursing Homes. J Nutr Health Aging 2020. 24:1047-1052. doi: 10.1007/s12603-020-1435-z.

35. Ohaegbulam KC, Swalih M, Patel P, Smith MA, Perrin R: Vitamin D Supplementation in COVID-19 Patients: A Clinical Case Series. Am J Ther 2020. 27:e485-e490. doi: 10.1097/MJT.0000000000001222.

36. Katz J, Yue S, Xue W. Increased risk for COVID-19 in patients with vitamin D deficiency. Nutrition 2021. 84:111106. doi: 10.1016/j.nut.2020.111106.

37. Luo $X$, Liao $Q$, Shen $Y$, Li H, Cheng L. Vitamin D Deficiency Is Associated with COVID-19 Incidence and Disease Severity in Chinese People (corrected). J Nutr 2021. 151:98-103. doi: 10.1093/jn/nxaa332.

38. Tehrani S, Khabiri N, Moradi H, Mosavat MS, Khabiri SS: Evaluation of vitamin D levels in COVID-19 patients referred to Labafinejad hospital in Tehran and its relationship with disease severity and mortality. Clin Nutr ESPEN 2021. 42:313-317. doi: 10.1016/j.clnesp.2021.01.014.

39. Meltzer DO, Best TJ, Zhang H, Vokes T, Arora VM, Solway J: Association of Vitamin D Levels, Race/Ethnicity, and Clinical Characteristics With COVID-19 Test Results. JAMA Netw Open 2021. 4:e214117. doi: 10.1001/jamanetworkopen.2021.4117.

40. Gavioli EM, Miyashita H, Hassaneen O, Siau E: An Evaluation of Serum 25-Hydroxy Vitamin D Levels in Patients with COVID-19 in New York City. J Am Coll Nutr 2021. Feb 19:1-6. doi: 10.1080/07315724.2020.1869626.

41. Jevalikar G, Mithal A, Singh A, Sharma R, Farooqui KJ, Mahendru S, Dewan A, Budhiraja S: Lack of association of baseline 25-hydroxyvitamin $D$ levels with disease severity and mortality in Indian patients hospitalized for COVID-19. Sci Rep 2021. 11:6258. doi: 10.1038/s41598-021-85809-y.

42. Ma H, Zhou T, Heianza Y, Qi L: Habitual use of vitamin D supplements and risk of coronavirus disease 2019 (COVID-19) infection: a prospective study in UK Biobank. Am J Clin Nutr 2021. 113(5):1275-1281. doi: 10.1093/ajcn/nqaa381.

43. Murai IH, Fernandes AL, Sales LP, Pinto AJ, Goessler KF, Duran CSC, Silva CBR, Franco AS, Macedo MB, Dalmolin HHH, Baggio J, Balbi GGM, Reis BZ, Antonangelo L, Caparbo VF, Gualano B, Pereira RMR: Effect of a Single High Dose of Vitamin D3 on Hospital Length of Stay in Patients With Moderate to Severe
COVID-19: A Randomized Clinical Trial. JAMA 2021. 325(11):1053-1060. doi: 10.1001/jama.2020.26848.

44. Entrenas Castillo M, Entrenas Costa LM, Vaquero Barrios JM, Alcalá Díaz JF, López Miranda J, Bouillon R, Quesada Gomez JM: "Effect of calcifediol treatment and best available therapy versus best available therapy on intensive care unit admission and mortality among patients hospitalized for COVID19: A pilot randomized clinical study". J Steroid Biochem Mol Biol 2020. 203:105751. doi: 10.1016/j.jsbmb.2020.105751.

45. Tapiero H, Tew KD: Trace elements in human physiology and pathology: zinc and metallothioneins. Biomed Pharmacother 2003. 57(9):399-411. doi: 10.1016/s0753-3322(03)00081-7.

46. Savarino G, Corsello A, Corsello G: Macronutrient balance and micronutrient amounts through growth and development. Ital J Pediatr 2021. 47(1):109. doi: 10.1186/s13052-021-01061-0.

47. McCall KA, Huang C, Fierke CA: Function and Mechanism of Zinc Metalloenzymes. J Nutrition 2000. 130: 1437S-1446S. doi: 10.1093/jn/130.5.1437S.

48. Laity JH, Lee BM, Wright PE: Zinc finger proteins: new insights into structural and functional diversity. Curr Opin Struct Biol 2001.11(1):39-46. doi: 10.1016/s0959-440x(00)00167-6.

49. Baltaci AK, Yuce K, Mogulkoc R: Zinc Metabolism and Metallothioneins. Biol Trace Elem Res 2018. 183(1):22-31. doi: 10.1007/s12011-017-1119-7.

50. Pisano $\mathrm{M}$, Hilas $\mathrm{O}$ : Zinc and Taste Disturbances in Older Adults: A Review of the Literature. Consult Pharm 2016. 31(5):267-70. doi: 10.4140/TCP.n.2016.267.

51. Barnett JB, Hamer DH, Meydani SN: Low zinc status: a new risk factor for pneumonia in the elderly? Nutr Rev 2010. 68(1):30-7. doi: 10.1111/j.17534887.2009.00253.x.

52. Rouadi PW, Idriss SA, Bousquet J: Olfactory and taste dysfunctions in COVID-19. Curr Opin Allergy Clin Immunol 2021. 21(3):229-244. doi: $10.1097 / \mathrm{ACl} .0000000000000735$.

53. Shah MA, Rasul A, Yousaf $R$, Haris $M$, Faheem $H I$, Hamid A, Khan H, Khan AH, Aschnar M, Batiha GE: Combination of natural antivirals and potent immune invigorators: A natural remedy to combat COVID-19. Phytother Res 2021. doi: 10.1002/ptr.7228.

54. Panoutsopoulos AA: Known drugs and small molecules in the battle for COVID-19 treatment. Genes Dis 2020. 7(4):528-534. doi: 10.1016/j.gendis.2020.06.007. 
55. Gammoh NZ, Rink L: Zinc in infection and inflammation. Nutrients 2017. 9:624. doi: $10.3390 /$ nu9060624.

56. Read SA, Obeid S, Ahlenstiel C, Ahlenstiel G: The role of zinc in antiviral immunity. Adv Nutr 2019. 10:696710. doi: 10.1093/advances/nmz013.

57. Liu MJ, Bao S, Gálvez-Peralta M: ZIP8 regulates host defense through zinc-mediated inhibition of NFкB. Cell Rep $2013 . \quad$ 01:009. doi: 10.1016/j.celrep.2013.01.009

58. Rani I, Goyal A, Bhatnagar M, Manhas S, Goel P, Pal A, Prasad R: Potential molecular mechanisms of zincand copper-mediated antiviral activity on COVID-19. Nutr Res 2021. 92:109-128. doi: 10.1016/j.nutres.2021.05.008.

59. Thomas S, Patel D, Bittel B, Wolski K, Wang Q, Kumar A, II'Giovine ZJ, Mehra R, McWilliams C, Nissen SE, Desai MY: Effect of High-Dose Zinc and Ascorbic Acid Supplementation vs Usual Care on Symptom Length and Reduction Among Ambulatory Patients With SARS-CoV-2 Infection: The COVID A to $Z$ Randomized Clinical Trial. JAMA Netw Open 2021. 4(2):e210369. doi: 10.1001/jamanetworkopen.2021.0369.

60. Szarpak L, Pruc M, Gasecka A, Jaguszewski MJ, Michalski T, Peacock FW, Smereka J, Pytkowska K, Filipiak KJ: Should we supplement zinc in COVID-19 patients? Evidence from meta-analysis. Pol Arch Intern Med 2021. Jun 28. doi: 10.20452/pamw.16048.

61. Kaufman-Shriqui V, Navarro DA, Raz O, Boaz M: Multinational dietary changes and anxiety during the coronavirus pandemic-findings from Israel. Isr J Health Policy Res 2021. 10:28. doi: 10.1186/s13584021-00461-1.

62. Butler T, Kerley CP, Altieri N, Alvarez J, Green J, Hinchliffe J, Stanford D, Paterson K: Optimum nutritional strategies for cardiovascular disease prevention and rehabilitation (BACPR). Heart 2020. 106(10):724-731. doi: 10.1136/heartjnl-2019315499.

63. Sattar N, Valabhji J: Obesity as a Risk Factor for Severe COVID-19: Summary of the Best Evidence and Implications for Health Care. Curr Obes Rep 2021. 10:1-8. doi: 10.1007/s13679-021-00448-8.

64. Raeisi T, Mozaffari H, Sepehri N, Darand M, Razi B, Garousi N, Alizadeh M, Alizadeh S: The negative impact of obesity on the occurrence and prognosis of the 2019 novel coronavirus (COVID-19) disease: a systematic review and meta-analysis. Eat Weight
Disord 2021. 11:1-19. doi: 10.1007/s40519-02101269-3.

65. Yates T, Zaccardi F, Islam N, Razieh C, Gillies CL, Lawson CA, Chudasama Y, Rowlands A, Davies MJ, Docherty AB, Openshaw PJM, Baillie JK, Semple MG: ISARIC4C investigators, Khunti K. Obesity, Ethnicity, and Risk of Critical Care, Mechanical Ventilation, and Mortality in Patients Admitted to Hospital with COVID-19: Analysis of the ISARIC CCP-UK Cohort. Obesity (Silver Spring) 2021. 29(7):1223-1230. doi: 10.1002/oby.23178.

66. Peña JE, Rascón-Pacheco RA, Ascencio-Montiel IJ, González-Figueroa E, Fernández-Gárate JE, MedinaGómez OS, Borja-Bustamante $\mathrm{P}$, Santillán-Oropeza JA, Borja-Aburto VH: Hypertension, Diabetes and Obesity, Major Risk Factors for Death in Patients with COVID-19 in Mexico. Arch Med Res 2021. 52(4):443449. doi: 10.1016/j.arcmed.2020.12.002.

67. Zeigler Z: COVID-19 Self-quarantine and Weight Gain Risk Factors in Adults. Curr Obes Rep 2021. 12:111. doi: 10.1007/s13679-021-00449-7.

68. Ghauri MI, Bareeqa SB, Riaz A, Kumar A: Redundancy Is of No Good; latrogenic Hypervitaminosis D: A Rare Case of Persistent Vomiting Due to Hypercalcemia. Clin Med Insights Case Rep 2019. 12:1179547619828688. doi: $10.1177 / 1179547619828688$.

69. Reider CA, Chung RY, Devarshi PP, Grant RW, Hazels Mitmesser S: Inadequacy of Immune Health Nutrients: Intakes in US Adults, the 2005-2016 NHANES. Nutrients 2020. 12(6):1735. doi: 10.3390/nu12061735.

70. Ratajczak AE, Rychter AM, Zawada A, Dobrowolska A, Krela-Kaźmierczak I: Do Only Calcium and Vitamin D Matter? Micronutrients in the Diet of Inflammatory Bowel Diseases Patients and the Risk of Osteoporosis. Nutrients 2021. 13(2):525. doi: $10.3390 /$ nu13020525.

71. Toninello P, Montanari A, Bassetto F, Vindigni V, Paoli A: Nutritional Support for Bariatric Surgery Patients: The Skin beyond the Fat. Nutrients 2021. 13(5):1565. doi: $10.3390 /$ nu13051565.

72. Marrone G, Guerriero C, Palazzetti D, Lido P, Marolla A, Di Daniele F, Noce A: Vegan Diet Health Benefits in Metabolic Syndrome. Nutrients 2021. 13(3):817. doi: 10.3390/nu13030817.

73. Wu J, Meng QH: Current understanding of the metabolism of micronutrients in chronic alcoholic liver disease. World J Gastroenterol 2020. 26(31):4567-4578. doi: 10.3748/wjg.v26.i31.4567. 